\title{
The relation between caries activity and hospitalization length in children
}

\author{
Stroianu Amiel, Klein Inesa, Cohen Ornit, Zilberman Uri \\ Pediatric Dental Unit, Barzilai Medical University Center, Israel
}

Correspondence: Dr Uri Zilberman, Head of the Pediatric Dental Unit, Barzilai Medical University Center, Address: 2nd Hahistadrut st, 7830604, Ashkelon, Israel, Email ori@barzi.health.gov.il

Received: July 26, 2018 | Published: August 14, 2018

Copyright@ 2018 Amiel et al. This is an open access article distributed under the terms of the Creative Commons Attribution License, which permits unrestricted use, distribution, and reproduction in any medium, provided the original author and source are credited.

\begin{abstract}
Dental caries affects the well-being and quality of life of children and their families. Untreated carious lesions may led to infections and hospitalization. The aim of this study was to determine the effect of untreated carious lesions on the recovery period of children hospitalized due to childhood diseases at Barzilai Medical University Center in Ashkelon, Israel. The oral condition of 159 children, 77 boys and 82 girls, hospitalized in the pediatric department, due to various childhood diseases, was determined after the routine morning examination, after informed consent was obtained from the parents. Routine tests results at hospitalization and length of hospitalization in days were recorded after the children were released from the department. Statistical analyses were performed in order to determine the main factors affecting hospitalization length. The main statistically significant factor $(\mathrm{P}<0.05)$ was presence of carious lesion. The results showed that carious activity may affect the recovery time of children and the length of hospitalization. Reducing the hospitalization time of children will affect the financial burden on the health department and on the family of the hospitalized children.
\end{abstract}

Keywords: caries, hospitalization, childhood diseases

\section{Abbreviations}

QoL; quality of life; HRQL, health-related Quality of life; dmft, decayed filled missing teeth; URT, upper respiratory tract; GI, gastrointestinal; WBC, white blood count; HCT, hematocrit; HB, hemoglobin; GLM, general linear model

\section{Introduction}

Dental caries is the most unmet health care need of children. It is the most common chronic bacterial infection of childhood- $8.4 \%$ of 2-year old children in USA had at least one decayed or filled tooth, and by the age of $5,40.4 \%$ of the children were affected. ${ }^{1}$ The children at increased risk for problems with oral health and access to care are from poor and minority families- in USA the General Accounting Office reported that poor children had 5 times more untreated decay then children from higher income families. ${ }^{2}$ Children who came from poor families suffer 12 times the number of restricted activity days because of dental problems and had only half the number of dental visits compared to children from higher income families. ${ }^{3}$

Quality of life (QoL) was defined as “a person's sense of well-being that stems from satisfaction or dissatisfaction with the areas of life that are important to him/her". ${ }^{4}$ Health contributes to quality of life and the true impact of health and disease on quality of life is known as health-related quality of life (HRQL). Oral health is an integral part of the general health and contributes to overall health-related quality of life. The oral cavity contributes to HRQL at both biologic and social psychological levels and when oral health is compromised, overall health may also be adversely affected..$^{5}$ Dental treatment of rampant caries and early childhood caries improved dramatically the quality of life index for young children, as reported by the children and their parents. ${ }^{6-8}$

The pathobiology of caries involves complex communities of bacterial species. Molecular analysis of bacterial species associated with childhood caries showed that $S$. sanguis was associated with health while Actinomyces gerencseriae, Bifidobacterium, S. mutans, Veillonella, $S$. salivarius, $S$. constellatus, $S$. parasanguis and Lactobacillus fermentum were associated with early childhood caries. ${ }^{9}$ Specific immune defense against the bacteria that are commonly held responsible for the initiation of dental caries, the "mutans streptococci" was thought to depend upon salivary antibodies. The major salivary immunoglobulin is secretory IgA, which occurs at widely ranging concentrations in resting whole saliva. ${ }^{10}$ In addition the oral cavity receives Igs derived from the circulation by transudation. These comprise IgM, IgG and IgA roughly in proportion to their presence in blood plasma, but normally representing only small amounts in comparison to the levels of salivary IgA. ${ }^{11}$ In young children, 3-5yearold, secretory IgA and anti-S. mutans IgA, IgM and IgG antibodies levels were not significantly different between caries free and children affected by rampant caries. ${ }^{12}$ In contrary, severe caries in children affected the systemic parameters of inflammation. The concentration of systemic IgG against $S$. mutans was significantly correlated with dmft. ${ }^{13}$ It is possible that dental caries also interferes with systemic factors, thereby negatively influencing the general health. The relation of oral disorders and several systemic diseases was established. History of strokes was associated with a higher experience of caries and more gingival and periodontal problems in adults. ${ }^{14}$ Oral condition 
is a significant cause of morbidity and potential mortality for children undergoing hematopoietic cell transplant. ${ }^{15}$

The hypothesis of this research was that if the presence of carious lesions affects the systemic immunologic system, the results will be observed even in common childhood diseases and will influence the recovery period of children, as determined by hospitalization periods.

\section{Materials and methods}

\section{Subjects}

159 children, aged 2-14.5years, were examined. The children were hospitalized for different health problems during 2014-2016, at the pediatric department of the Barzilai Medical Center, Ashkelon, Israel. In order to be included in the study, the parents were present at the time of clinical examination and signed an informed consent form. The parents were given a questioner regarding the general health of their child, reasons for hospitalization as well as personal data and socioeconomic details. Ethical approval for this study was granted by the Helsinki comity of the Barzilai Medical Center.

\section{Clinical procedures}

During the morning visit only those children whom their parents signed the informed consent were also checked for carious lesions by one dentist that accompanied the visit and then recorded the findings in the designated file. Each child was checked in sitting position on their bed, assisted by a dental assistant and using a head light and a single use mirror. All carious lesions were recorded using a simple scale of classification, where 0 represented "no carious lesion", and 1 represented "carious lesion". All data was recorded at the time of the visit and the parents were given oral hygiene instructions for their children. The medical problem for which the children were admitted was also recorded and by using their clinical chart all relevant parameters was recorded.

For statistical analysis, the causes for hospitalization were divided into three major groups that were defined as D1 for those who were admitted for upper respiratory tract (URT) disease, D2 for gastrointestinal (GI) cause, and D3 for all other problems.

All routine tests were performed and recorded for each hospitalized child during their stay. Those parameters were recorded and noted as follows:

Child's fever on admission (Ti), antibiotic treatment (AB) where $0=$ not relevant for child's hospitalization reason, $1=$ relevant and Amoxicillin given and $2=$ relevant and other $\mathrm{AB}$ was administered during child's hospitalization. The blood parameters recorded in this study consisted of white blood count (WBC), hematocrit (HCT) and hemoglobin (HB) at admission.

\section{Statistical analyses}

The data was evaluated statistically using the SAS program. General Linear Model (GLM) procedure was used to assess the variables that affected the hospitalization period of the children and to determine if there were any differences between boys and girls.

\section{Results}

77 boys and 82 girls, aged 2-14.5years, were included in this study. The mean age of the boys was 7.54years $(\mathrm{SD}=3.79)$ and for the girls 7.9years $(\mathrm{SD}=3.86)$. Figure 1 shows the histogram of hospitalization time for all children included in the research.

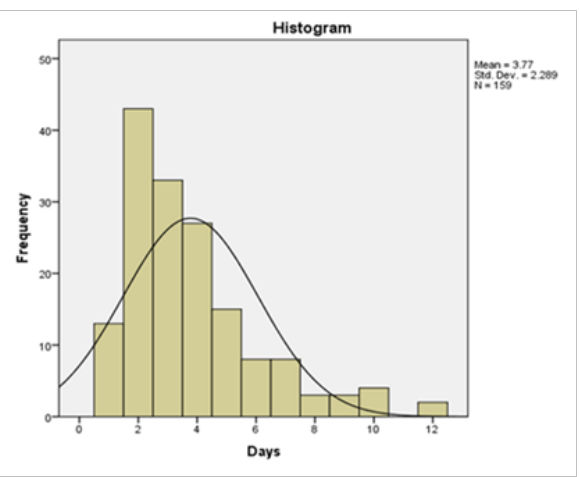

Figure I Histogram of hospitalization days.

Forty one boys showed no visible caries activity, while 33 boys showed one or more teeth affected by dental caries. Among the girls, 41 showed no caries activity at all, while 44 girls presented with one or more teeth affected by caries lesion. All groups were then divided according to the mean time of hospitalization. The "caries positive" boys spent 4.3 (SD 2.38) days in the pediatric department while the "caries negative" boys were hospitalized for 3.2 (SD 1.6) days. The "caries positive" girls spent a mean time of 4.43 (SD 2.76) days and the "caries negative" girls were hospitalized for 3.22 (SD 2.03) days (Figure 2). Student's T-test was performed in order to compare the hospitalization time in caries free girls and boys compared to caries positive girls and boys. The results show a strong statistical significance for the girls, $\mathrm{P}=0.024$, and for the boys $\mathrm{P}=0.019$.

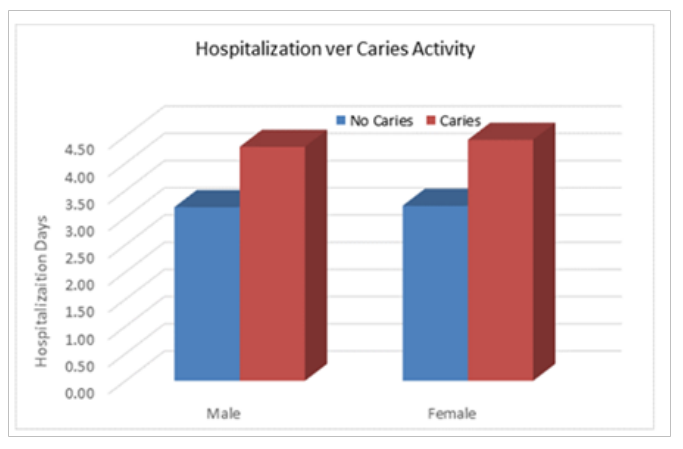

Figure 2 Hospitalization time versus caries activity.

The caries positive boys and girls groups were divided by the number of teeth affected, group $1=1-2$ teeth affected, and group $2=>2$ teeth affected. Statistical analysis showed no significant differences in hospitalization time between the two groups of caries positive boys $(\mathrm{P}=0.561)$ or girls $(\mathrm{P}=0.347)$.

Table 1 describes the number of children in relation to the clinical conditions at hospitalization and caries activity. There was no correlation between the caries activity and type of the disease for which the child was hospitalized.

Table I Disease cross-tabulation

\begin{tabular}{llllll}
\hline Gender & $\begin{array}{l}\text { Caries } \\
\text { activity }\end{array}$ & D I URT & D2 GI & D3Other & $\begin{array}{l}\text { P } \\
\text { value }\end{array}$ \\
\hline Boys & Yes & II & 8 & 14 & 0.282 \\
Boys & No & 9 & 7 & 25 & \\
Girls & Yes & 12 & 10 & 22 & 0.986 \\
Girls & No & 10 & 11 & 20 & \\
\hline
\end{tabular}


Table 2 shows the correlation between the diseases and the hospitalization time. No significant correlations were found. The mean hospitalization time was 3.35 days for GI, 3.98 days for upper respiratory diseases and 3.79 days for other diseases

A Spearman's rho correlation coefficient was calculated between the parameters related to the disease that led to their hospitalization and hospitalization time (Table 3), in order to determine the influence of each parameter on the duration of hospitalization and therefore the healing time length of each child. The results show that only caries activity and the temperature when accepted had significant effect on length of hospitalization.

ANOVA statistics with days of hospitalization as the dependent variable showed that caries or caries and temperature in together showed significant results (Table 4).

Table 2 Disease type and hospitalization time

\begin{tabular}{|c|c|c|c|c|c|c|c|c|c|}
\hline Days & $\mathbf{N}$ & Mean & $\begin{array}{c}\text { Std. } \\
\text { Deviation }\end{array}$ & Std. Error & $\begin{array}{l}95 \% \text { Confidence } \\
\text { Interval for Mean }\end{array}$ & & Minimum & Maximum & Sig. \\
\hline & & & & & Lower Bound & Upper Bound & & & \\
\hline Lung & 43 & 3.98 & 2.355 & 0.359 & 3.25 & 4.7 & 0 & 10 & 0.469 \\
\hline GI & 37 & 3.35 & 2.058 & 0.338 & 2.67 & 4.04 & 0 & 12 & \\
\hline Other & 84 & 3.89 & 2.733 & 0.298 & 3.3 & 4.49 & I & 16 & \\
\hline Total & 164 & 3.79 & 2.495 & 0.195 & $3.4 I$ & 4.18 & 0 & 16 & \\
\hline
\end{tabular}

Table 3 Correlations

\begin{tabular}{|c|c|c|c|c|c|c|c|c|}
\hline \multicolumn{2}{|c|}{ Correlation coefficient } & \multirow{2}{*}{$\begin{array}{l}\text { Days } \\
\text { I }\end{array}$} & \multirow{2}{*}{$\begin{array}{l}\text { Caries } \\
.243^{* *}\end{array}$} & \multirow{2}{*}{$\begin{array}{l}\text { Age } \\
0.058\end{array}$} & \multirow{2}{*}{$\begin{array}{l}\text { tem in } \\
.176^{*}\end{array}$} & \multirow{2}{*}{$\begin{array}{l}\text { WBC } \\
0.04\end{array}$} & \multirow{2}{*}{$\begin{array}{l}\text { HB } \\
0.004\end{array}$} & \multirow{2}{*}{$\begin{array}{l}\text { HCT } \\
0.024\end{array}$} \\
\hline Spearman's rho & Days & & & & & & & \\
\hline & Caries & $.243 * *$ & I & 0.032 & -0.058 & -0.002 & 0.102 & 0.068 \\
\hline & Age & 0.058 & 0.032 & 1 & $-.29 \mid * *$ & -0.149 & $.537 * *$ & $.504 * *$ \\
\hline & tem in & $.176 *$ & -0.058 & $-.29 \mid * *$ & 1 & 0.144 & $-.30 \mathrm{I} * *$ & $-.317 * *$ \\
\hline & WBC & 0.04 & -0.002 & -0.149 & 0.144 & I & -0.028 & -0.036 \\
\hline & $\mathrm{HB}$ & 0.004 & 0.102 & $.537 * *$ & $-.301 * *$ & -0.028 & $\mathrm{I}$ & $.893 * *$ \\
\hline & HCT & 0.024 & 0.068 & $.504 * *$ & $-.317 * *$ & -0.036 & $.893 * *$ & I \\
\hline
\end{tabular}

**. Correlation is significant at the 0.0 I level (2-tailed).

*. Correlation is significant at the 0.05 level (2-tailed).

Table 4 ANOVA statistics

\begin{tabular}{lcclll}
\hline Model & Sum of squares & df & Mean square & F & Sig \\
\hline I Regression & 53.748 & $\mathrm{I}$ & 53.748 & 10.785 & $0.00 \mathrm{I}^{\mathrm{b}}$ \\
Residual & 767.502 & $\mathrm{I} 54$ & 4.984 & & \\
Total & 821.250 & 155 & & & \\
2 Regression & 89.347 & 2 & 44.673 & 9.339 & $0.000^{\mathrm{c}}$ \\
Residual & 731.903 & $\mathrm{I} 53$ & 4.784 & & \\
Total & 821.250 & $\mathrm{I} 55$ & & & \\
\hline
\end{tabular}

a. Dependent Variable: Days

b. Predictors: (Constant), Caries

c. Predictors: (Constant), Caries, Temp in

\section{Discussion}

It is already well established among pediatric dental clinicians that there is a strong correlation between one's oral health and healing prognosis. By conducting this preliminary study, we demonstrated what is already discussed and reported by many others, that most of the children who repeatedly visit our offices for acute and chronic dental problems, are those children who spend much more time at hospital for various reason of hospitalization. Furthermore, the results show that regardless to the severity of the illness or even the main cause of hospitalization, those children with poor oral hygiene, and with numerous untreated carious lesions always will checkout of hospital later than those who present no carious lesion and therefore no untreated oral inflammatory foci. The differences between caries positive and caries negative children in hospitalization time was significant- the caries active children spent 33\% more time in the pediatric department with no relation to the kind of the disease. Odontogenic infections may result in local, systemic and even potentially life-threatening complications. ${ }^{16}$ There is an association between preventive measures against carious activity (like 
fluoridation of the water), and hospitalization due to dental infections among children and this effect is more prominent in populations with lower socioeconomic status. ${ }^{17}$ Oral health is more than healthy teeth. Oral diseases and disorders have a direct and devastating impact on overall health and well-being throughout life. ${ }^{18}$ Caries and other oral conditions can lead to pain, infections and loss of function. These outcomes can affect learning, nutrition and other activities necessary for normal growth and development. ${ }^{19}$ Treatment of carious lesions in children may reduce the hospitalization burden on the health department of any country and the suffering from the child and the family due to long hospitalization time.

\section{Acknowledgements}

None.

\section{Conflict of interest}

The author declares no conflict of interest.

\section{References}

1. US Department of Health and Human Services. Oral health in America: A Report of the Surgeon General. Rockville MD: US Department of Health and Human Services, National institute of dental and cranial research, USA: National Institute of Health; 2000.

2. Lewis CW, Grossman DC, Domoto PK, et al. The role of pediatrician in the oral health of children: a national survey. Pediatrics. 2000;106(6):e84.

3. US General Accounting Office. Oral health: dental disease is a chronic problem among low income populations. USA: GAO; 2000. 49 p.

4. Becker M, Diamond R, Sainfort F. A new patient focused index for measuring quality of life in persons with severe and persistent mental illness. Quality of life research. 1993;2(4):239-251.

5. Gift HC, Atchison KA. Oral health, health and health-related quality of life. Med Care. 1995;33(11 Suppl):57-77.

6. Thomas CW, Primosch RE. Changes in incremental weight and well-being of children with rampant caries following complete dental rehabilitation. Pediatric Dentistry. 2002:24(2):109-113.

7. Filstrup SL, Briskie D, da Fonseka M, et al. early childhood disease and quality of life: child and parent perspectives. Pediatric Dentistry. 2003;25(5):431-440.
8. Anderson HK, Drummond BK, Thomson WM. Changes in aspects of children's oral-health-related quality of life following dental treatment under general anaesthesia. Int J Paediatr Dent. 2004;14(5):317-325.

9. Becker MR, Paster BJ, Leys EJ, et al. Molecular analysis of bacterial species associated with childhood caries. J Clinical Microbiology. 2002;40(3):1001-1009.

10. Russell MW, Hajishengallis G, Childers NK, et al. Secretory immunity in defense against cariogenic mutans Streptococci. Caries Research. 1999;33(1):4-15.

11. Brandtzaeg P. Salivary immunoglobulins; in Tenovuo JO editor. Human Saliva: Clinical Chemistry and Microbiology. Boca Raton: CRC Press; 1989;2:1-54.

12. Naspitz GMCC, Nagao AT, Mayer MPA, et al. Anti-Streptococcus mutans antibodies in saliva of children with different degrees of dental caries. Pediatric Allergy and Immunology. 1999;10(2):143-148.

13. deSoet JJ, Schriks MCM, Kratz E, et al. Dental caries related to plasma IgG and Alpha1-Acid Glycoprotein. Caries Research. 2003;37:79-84

14. Maupome G, Gullion CM, White BA, et al. Oral disorders and chronic systemic diseases in very old adults living in institutions. Spec Care Dentist. 2003;23(6):199-208.

15. Majorana A, Schubert MM, Porta F, et al. Oral complications of pediatric hematopoietic cell transplantation: diagnosis and management. Support Care Cancer. 2000;8:347-348.

16. Beltran-Aguilar ED, Barker LK, Canto MT, et al. Surveillance for dental caries, dental sealents, tooth retention, edentulism and enamel fluorosis: United States, 1998-1994 and 1999-2002. MMWR Surveil Summ. 2005;54(3):1-43.

17. Klivitsky A, Tasher D, Stein M, et al. Hospitalizations for dental infectionsOptimally fluoridated areas in Israel. JADA. 2015;146(3):179-183.

18. US department of Health and Human Services. National call to Action to Promote Oral health. NIH Publication No. 03-5303, US: Office of the Surgeon General (US); 2003.

19. Acs G, Lodolini G, Kaminsky S, et al. Effect of nursing caries on body weight in a pediatric population. Pediatr Dent. 1992;14(5):302-305. 